\title{
Modifikasi Struktur Bangunan Gedung Hotel Fave Dengan Menggunakan Rangka Baja
}

\author{
Imron Hamzah $^{1 *}$, Eka Susanti ${ }^{2}$, dan Jaka Propika ${ }^{3}$ \\ ${ }^{1,2,3}$ Program Studi Teknik Sipil, FTSP, ITATS \\ 1*ihamzah08@gmail.com, ${ }^{2 *}$ ekasusanti2015@gmail.com
}

\begin{abstract}
The owner of Fave Hotel requested to have efficient structure of building which could be accomplished faster than reinforced concrete. Therefore, steel material which has the same characteristics as the owner desire was selected. The idea of redesigning the building structure by means of steel came out as it has some advantages such as high strength, uniformity, and ductility. The problems of calculation were focused on the results of remodeling the structure using steel and the structural behavior toward drift, seismic shear, and mass participation. In terms of remodeling the structure calculation using steel, the results were as follows: the main beam consisted of plate beam for floors 1-12 (transverse beam WF 350.175.7.11 and long beam WF 400.200.8.13) and plate beam for roof (transverse beam WF 300.150.6,5.9 and long beam WF 350.175.7.11). The major column included floors 1-2 (Hbeam 500.500.20.30), floors 1-2 lobby entrance (WF 400.200.8.13), floors 3-6 (Hbeam 500.500.15.30), and floors 7-12 (WF 500.300.12.22), Bresing (Hbeam 200.200.10.16). Meanwhile, the structural behaviour of Fave Hotel building post-redesigning had met the seismic loading and analysis by SAP 2000: mass participation ratio was 99\% > 90\%, fundamental period reached 1.52 second, shear force of seismic base was more than $85 \%$, permitted shear force and shear direction went to axes $X$ and $Y$, the biggest inter-storey drift was $12.87 \mathrm{~mm}$, thus it did not exceed the permitted drift $38.50 \mathrm{~mm}$.
\end{abstract}

Keywords: Drift, mass participation, modification, seismic shear force, steel frame.

\begin{abstract}
Abstrak
Struktur bangunan hotel fave didisain dengan material beton bertulang, namun pihak owner menginginkan struktur yang lebih efisien, dalam hal berat struktur. Maka dipilihlah material baja dengan karateristik yang sama seperti yang di inginkan pihak owner. Ide redisain menggunakan baja ini timbul karena baja memiliki berbagai keunggulan dibanding beton bertulang. Diantaranya adalah, dengan inersia yang sama, baja memiliki kapasitas yang lebih tinggi, baja juga memiliki keseragaman kualitas material yang lebih terjamin karena hasil buatan pabrik. Selain itu, baja juga memiliki daktilitas yang lebih tinggi dibanding beton bertulang dan berat struktur yang lebih ringan. Tujuan dari penelitian ini adalah meredisain struktur dengan menggunakan material baja dan mengetahui perilaku struktur terhadap drift, gaya geser gempa dan partipasi massa. Hasil redisain struktur dengan menggunakan baja adalah: Balok utama dari lantai 1-12 (balok melintang WF 350.175.7.11 dan balok memanjang WF 400.200.8.13) dan balok atap (balok melintang WF 300.150.6,5.9 dan balok memanjang WF 350.175.7.11). Kolom utama lantai 1-2 (Hbeam 500.500.20.30), kolom lantai 1-2 lobby entrance (WF 400.200.8.13), kolom lantai 3-6 (Hbeam 500.500.15.30), dan kolom lantai 7-12 (WF 500.300.12.22). Bresing menggunakan Hbeam 200.200.10.16. Untuk perilaku struktur diperoleh dari hasil analisa program SAP 2000, hasil analisisnya adalah :Partisipasi massa memiliki rasio 99\% > 90\%, Periode fundamental mencapai waktu 1,52 detik, Gaya geser dasar gempa mencapai lebih dari $85 \%$ gaya geser ijin dengan arah gesernya lebih mengarah ke sumbu X dan Y, Simpangan antar lantai terbesar adalah 12,87 mm sehingga tidak lebih dari simpangan ijin sebesar $38,50 \mathrm{~mm}$.
\end{abstract}

Kata kunci: Drift, Gaya Geser Gempa, Modifikasi, Partipasi Massa, Rangka Baja

\section{Pendahuluan}

Pada struktur bangunan hotel fave, pihak owner menginginkan struktur yang lebih efisien, dalam hal berat struktur. Maka dipilihlah material baja dengan karakteristik yang sama seperti yang di inginkan pihak owner. 
Untuk bahan studi ini di peroleh data perencanaan Hotel Fave Surabaya dengan jumlah total 13 lantai. Dengan konstruksi struktur baja, dimana baja yang digunakan adalah kolom menggunakan hbeam, balok menggunakan $w f$ (wide flange) dan plat lantai menggunakan perpaduan antara beton yang berbekisting plat bondek dengan berisi tulangan wiremesh, serta pengaku pada kolom berupa bresing agar mampu menahan gaya lateral yang terjadi.

Masalah dalam peritungan ini adalah bagaimana hasil remodeling perhitungan struktur dengan menggunakan baja dan bagaimana perilaku struktur terhadap drift, gaya geser gempa, partipasi massa. Dengan tujuan Mendapatkan hasil remodeling perhitungan struktur dengan menggunakan baja dan hasil perilaku struktur terhadap drift, gaya geser gempa, partipasi massa.

\section{Tinjauan Pustaka}

Dalam merencanakan gedung ini diperlukan pengetahuan dasar tentang profil baja baik dari studi literatur, jurnal-jurnal, dan skripsi seperti pada [7] Moh Rama Rosyd tentang "Perencanaan Gedung Parkir Dari Kontruksi Baja Dengan Lokasi Di Ft Unnes Dengan Menggunakan Plat Precast" yang menggunakan acuan [1] SNI 1729-2002 dan [6] LRFD pada perhitungannya dan penelitian [8] J Propika dkk 2019. Untuk memperkuat struktur gedung akibat gaya lateral dari gempa adalah dengan penggunaan bresing. Sehingga sistem gedung yang digunakan adalah Sistem Rangka Bresing Konsentrik Khusus (SRBKK). Selain itu diperlukan pengetahuan tentang perhitungan struktur secara keseluruhan misalnya tentang pembebanan maupun perhitungan struktur yang meliputi balok, sistem balok, kolom, bresing, dan sistem sambungan.

Baja profil adalah material baja yang di bentuk dan di buat dengan mutu tertentu dan sesuai kebutuhan struktural. dalam perencanaan ini menggunakan dua jenis profil yakni Hbeam (kolom dan bresing) dan wide flange (balok).

Perencanaan pembebanan pada struktur ini untuk beban mati dan beban hidup menggunakan [5] PPIUG 1983 dan [3] SNI 1727 - 2013 , untuk beban gempa menggunakan [2] SNI 1726 - 2012, serta untuk kontrol pada balok, kolom dan bresing menggunakan [4] SNI $1729-2015$.

\section{Metode}

Metode penelitian ini bersifat permodelan struktur dengan program SAP 2000. Dimulai dari disain struktur sekunder (pelat lantai, anak tangga, balok lift dan tangga). Dilanjutkan dengan disain struktur primer yang dimulai dari permodelan struktur baja dan pembebanan yang disesuaikan dengan pembebanan pada struktur eksisting (beton bertulang), yaitu beban mati, beban hidup dan beban gempa. Hasil analisis struktur digunakan untuk mendisain struktur primer (balok dan kolom) dan melihat perilaku struktur terhadap partipasi massa, drift dan gaya geser gempa.

Tabel 1. Rekap hasil perhitungan struktur sekunder

\begin{tabular}{|l|l|l|}
\hline \multicolumn{1}{|c|}{$\begin{array}{c}\text { Struktur sekunder yang } \\
\text { di tinjau }\end{array}$} & \multicolumn{1}{|c|}{ Fungsi } & \multicolumn{1}{c|}{ Profil } \\
\hline \multirow{3}{*}{ Pelat antai } & Lantai 1-mezzanine & Tebal 10cm (M10-200) \\
\cline { 2 - 3 } & Lantai 2-atap & Tebal 9cm (M8-200) \\
\hline \multirow{2}{*}{ Balok anak } & Balok anak 1-11 & WF 350.175.7.11 \\
\cline { 2 - 3 } Balok lift & Balok anak atap & WF 300.150.6,5.9 \\
\hline \multirow{5}{*}{ Tangga } & Balok lift penumpang & WF 350.175.7.11 \\
\hline \multirow{5}{*}{} & Pelat anak tangga & Plat tebal 3mm \\
\cline { 2 - 3 } & Pelat bordes & Plat tebal 9mm \\
\cline { 2 - 3 } & Pengaku anak tangga & Siku 50.50.5 \\
\cline { 2 - 3 } & Balok bordes & WF 100.50.5.7 \\
\cline { 2 - 3 } & Balok utama tangga & WF 200.100.5,5.8 \\
\cline { 2 - 3 } & Balok penumpu tangga & WF 200.100.5,5.8 \\
\hline
\end{tabular}




\section{Hasil dan Pembahasan}

\subsection{Struktur Sekunder}

Hasil disain dari struktur sekunder, yaitu plat bondek lengkap dengan tulangan wire mesh, balok anak, balok lift dan tangga dapat dilihat pada Tabel 1.

\subsection{Struktur Primer}

\section{A. Permodelan Struktur}

Permodelan struktur menggunakan SAP 2000 mengacu pada denah bangunan gambar 1. Dengan jumlah lantai adalah 13 lantai dan tinggi bangunan adalah 37,6m. Hasil permodelan SAP 3D dapat dilihat pada gambar 2

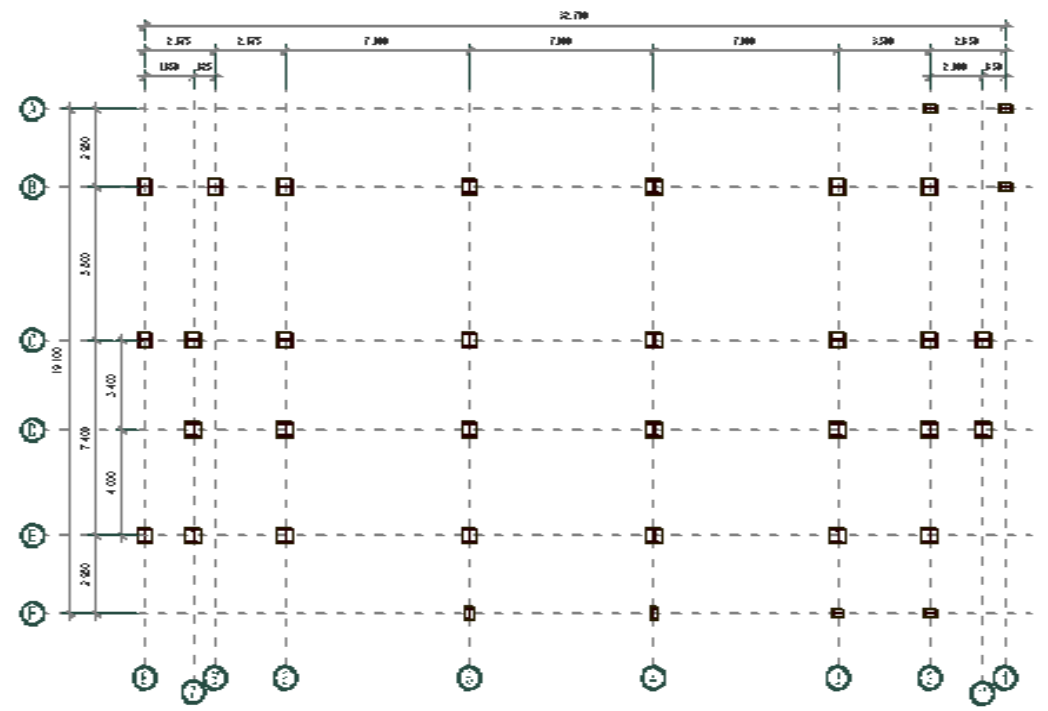

Gambar 1. Denah lantai atap

B. Kontrol Desain Desain struktur harus keamanan SNI 28472012.

1. Kontrol

2. Kontrol nilai

3. Kontrol

4. Kontrol

B.1. Kontrol Partisipasi massa SAP 2000, tertera

Tabel 2 Fave

.
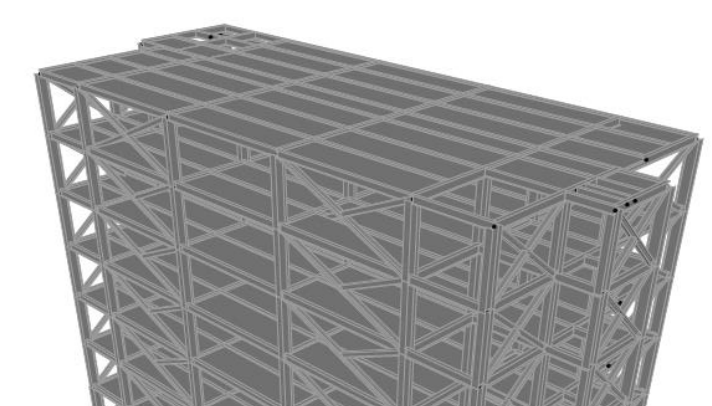

Gambar 2. Permodelan SAP 3D Struktur dikontrol terhadap standart kenyamaan yang sesuai dengan Kontrol tersebut adalah: partisipasi massa. respon spektrum. periode getar struktur. batas simpangan (drift)

\section{partisipasi massa} diperoleh dari hasil analisis pada tabel 2

\section{Rasio Partisipasi Massa Hotel Surabaya}

\section{Out put Case Step Num SumUX SumUY Out put Case Step Num SumUX SumUY}




\begin{tabular}{llllllll} 
MODAL & 1 & 0,027 & 0,663 & MODAL & 7 & 0,845 & 0,859 \\
\hline MODAL & 2 & 0,673 & 0,692 & MODAL & 8 & 0,846 & 0,909 \\
\hline MODAL & 3 & 0,675 & 0,693 & MODAL & 9 & 0,904 & 0,909 \\
\hline MODAL & 4 & 0,676 & 0,855 & MODAL & 10 & 0,904 & 0,942 \\
\hline MODAL & 5 & 0,842 & 0,855 & MODAL & 11 & 0,937 & 0,942 \\
\hline MODAL & 6 & 0,845 & 0,856 & MODAL & 12 & 0,937 & 0,989
\end{tabular}

Pada mode ke 9 struktur sdh mencapai partisipasi massa $>90 \%$

\section{B.2. Kontrol nilai respon spektrum}

Gedung ini direncanakan dengan Sistem Rangka Bresing Konsentris Khusus (SRBKK) dengan struktur keseuluruhan menggunakan material baja.
-Faktor pembesaran defleksi $(\mathrm{Cd}) \quad=5,5$
-Koefisien modifikasi respons $(\mathrm{R}) \quad=7$
- Faktor kuat- lebih sistem $(\Omega 0) \quad=2,5$

- Faktor keutamaan Ie = 1

- Berikut adalah nilai parameter respon spektrum untuk wilayah surabaya dengan kondisi tanah sedang

(kelas situs SD):

Penentuan koefisien nilai situs

$$
\begin{aligned}
& S_{S}=0,66 \text { dan } S_{1}=0,31 \\
& F_{a}=1,3 \text { dan Fv=1,9 } \\
& S_{M S}=\mathrm{Fa} \times S_{S}=0,56 \text { dan } S_{M 1}=\mathrm{Fv} \times S_{1}=0,31 \\
& S_{D S}=(2 / 3) \times \mathrm{Fa} \times S_{S}=0,56 \text { dan } S_{D 1}=(2 / 3) \times \mathrm{Fv} \times S_{1}=0,314 \\
& T=0 ; T_{0}=0,2\left(S_{D 1} / S_{D S}\right)=0,11 \text { dan } T_{1}=T_{S}=\left(S_{D 1} / S_{D S}\right)=0,56 \\
& \begin{array}{ll}
S_{a}=S_{D S}\left(0.4+0.6 \frac{T}{T_{0}}\right)=0,22 & ; T<T_{0} \\
S_{a}=S_{D S}=0,56 & ; T_{0} \leq T \leq T_{S} \\
S_{a}=\frac{S_{D S}}{T_{S}}=\frac{0,56}{0,56}=1 & ; T<T_{S}
\end{array}
\end{aligned}
$$

Cs maks $\quad=\mathrm{SDS} /(\mathrm{R} / \mathrm{Ie}) \quad=0,562 /(7 / 1) \quad=0,080$

$$
\begin{array}{ll}
\text { Cs hitungan } & =\mathrm{SD} 1 /(\mathrm{Ta} \times(\mathrm{R} / \mathrm{Ie}))=0,314 /(1,483 \times(7 / 1))=0,030 \\
\mathrm{Cs} \text { min } & =0,044 \times \mathrm{SDS} \times \mathrm{Ie}=0,044 \times 0,562 \times 1 \geq 0,01=0,025
\end{array}
$$

Cs $\min$ tambahan $=\mathrm{SD} 1 / 0,6 \mathrm{~g} /(\mathrm{R} / \mathrm{Ie}))=0,314 /(1,483 \times(7 / 1)) \quad=0,048$

(menentukan, karena mendekati nilai Cs maks 0,048)

Tabel 3. Hasil output SAP 2000v14 berat bangunan total

\begin{tabular}{ccccc} 
OutputCase & CaseType & GlobalFX & GlobalFY & GlobalFZ \\
\hline Text & Text & Kgf & Kgf & Kgf \\
\hline \multirow{5}{*}{ Combinatio } & & & 4354561, \\
& $n$ & $8,128 \mathrm{E}-10$ & $-5,93 \mathrm{E}-10$ & 5
\end{tabular}

Dari hasil analisis yang tertera di tabel 3, didapatkan nilai berat total struktur adalah 4354561,46kg maka :

Vstatik $=$ Cs $. \mathrm{Wt}=0,048.4354561 .46 \mathrm{~kg}=209453.11 \mathrm{~kg}$

Tabel 4. Hasil output Gaya Geser akibat Beban Gempa 


\begin{tabular}{clll}
\multirow{2}{*}{ Output Case } & \multirow{2}{*}{ Case Type } & GlobalFX & GlobalFY \\
\cline { 3 - 4 } & & Kgf & Kgf \\
\hline QUAKE X & LinRespSpec & 256557,32 & 83772,07 \\
\hline QUAKE Y & LinRespSpec & 86819,3 & 245008,12
\end{tabular}

Arah Gempa X: Vdinamik $<85 \%$. Vstatik $=256557,32 \mathrm{~kg}<1768035,15 \mathrm{~kg}(\operatorname{Not} \mathrm{OK})$

Arah Gempa Y: Vdinamik < 85\% . Vstatik $=245008,12 \mathrm{~kg}<178035,15 \mathrm{~kg}($ Not OK)

Karena dari kontrol di atas analisis struktur masih belum memenuhi syarat nilai akhir respon. Pada Pasal 11.1.4 SNI 03-1726-2012 Pasal 7.9.4.2 dijelaskan apabila gaya geser dasar hasil analisis kurang dari $85 \%$, maka harus diperbesar dengan factor skala $0,85 \times \frac{C s . W t}{V}$ maka:

Pembesaran dengan Faktor Skala:

Arah Gempa X: $0,85 \times \frac{C s \cdot W t}{V}=0,85 \times \frac{209453(11)}{256557,32}=0,694$

Arah Gempa Y; $0,85 \times \frac{C s \cdot W t}{V}=0,85 \times \frac{209453(11)}{245008,12}=0,727$

Tabel 5. Hasil output Gaya Geser akibat Beban Gempa dengan pembesaran

\begin{tabular}{lcll} 
Output Case & Case Type & GlobalFX & GlobalFY \\
\cline { 3 - 4 } & & Kgf & Kgf \\
\hline QUAKE X & LinRespSpec & 178022,30 & 60239,48 \\
\hline QUAKE Y & LinRespSpec & 60858,14 & 177781,00
\end{tabular}

Arah Gempa X: Vdinamik < 85\% . Vstatik $\quad=178022,30 \mathrm{~kg}<178035,15 \mathrm{~kg}(\mathrm{OK})$ Arah Gempa Y: Vdinamik < 85\% . Vstatik $\quad=177781,00 \mathrm{~kg}<178035,15 \mathrm{~kg}(\mathrm{OK})$

Setelah dikalikan dengan faktor skala untuk arah $X=0,694$ dan $Y=0,727$, dapat disimpulkan bahwa analisis struktur memenuhi persyaratan SNI 03-1726-2012 Pasal 7.8.

\section{B.3. Kontrol periode getar struktur.}

Untuk mencegah pengunaan struktur gedung yang terlalu fleksibel, nilai waktu getar alami fundamental (T) dari struktur gedung harus dibatasi.

Berdasarkan SNI 1726:2012, perioda fundamental struktur harus ditentukan dari :

Ta $a_{\text {minimum }}=C_{t} \cdot h_{n}{ }^{x}=0,0731 \cdot 37,6^{0,75}=1,11 \mathrm{~s}$

Ta $a_{\text {maksimum }}=C_{u} \cdot T a_{\text {minimum }}=1,4 \cdot 1,11=1,55 \mathrm{~s}$

Keterangan:

Besarnya koefisien tersebut tergantung dari nilai SD1, ketinggian struktur 37,6m dan sistem struktur rangka baja dengan bresing konsenterik sehingga pada Tabel 15 SNI 1726:2012 didapatkan nilai :

$C_{t}=0,0731 ; C_{u}=1,4 ; \mathrm{x}=0,75$ dan $h_{n}=37,6 \mathrm{~m}$

Dari hasil analisis SAP 2000 periode dan frekuensi struktur dapat dilihat pada Tabel 6

Tabel 6. Periode dan Frekuensi Struktur

\begin{tabular}{lcllllll} 
Out put Case & Step Num & $\begin{array}{l}\text { Period } \\
\text { (sec) }\end{array}$ & $\begin{array}{l}\text { Frequency } \\
\text { (Cyc/Sec) }\end{array}$ & Out put Case & Step Num & $\begin{array}{l}\text { Period } \\
\text { (sec) }\end{array}$ & $\begin{array}{l}\text { Frequency } \\
\text { (Cyc/Sec) }\end{array}$ \\
\hline MODAL & 1 & 1,5232 & 0,6565 & MODAL & 8 & 0,2479 & 4,0338 \\
\hline MODAL & 2 & 1,3967 & 0,7160 & MODAL & 9 & 0,2112 & 4,7354 \\
\hline MODAL & 3 & 0,9292 & 1,0762 & MODAL & 10 & 0,1606 & 6,2255 \\
\hline MODAL & 4 & 0,4744 & 2,1081 & MODAL & 11 & 0,1393 & 7,1765 \\
\hline MODAL & 5 & 0,4167 & 2,3996 & MODAL & 12 & 0,0785 & 12,745 \\
\hline MODAL & 6 & 0,2853 & 3,5055 & MODAL & 13 & 0,0723 & 13,823 \\
\hline MODAL & 7 & 0,2695 & 3,7105 & & & &
\end{tabular}


Kontrol waktu getar alami fundamental nilai $\mathrm{T}$
Taminimum
$<$ Ta $a_{\text {output sap }}$
$<$ Ta $a_{\text {maksimum }}$
$1,11 \mathrm{~s}$
$<1,52 \mathrm{~s}$
$<1,55 \mathrm{~s}$
$(\mathrm{OK})$

Maka berdasarkan kontrol waktu getar alami fundamental nilai T dari Output SAP masih dalam batas Periode yang diijinkan. Sehingga analisis struktur Hotel Fave Surabaya masih memenuhi syarat SNI 1726:2012 Pasal 7.8.2.

\section{B.4. Kontrol Batas Simpangan (Drift).}

Tabel 7. Kontrol Simpangan akibat Gempa arah X

\begin{tabular}{|c|c|c|c|c|c|c|c|}
\hline \multirow[t]{2}{*}{ Lantai } & \multirow[t]{2}{*}{ hi } & \multirow{2}{*}{ 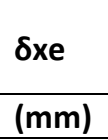 } & \multirow{2}{*}{$\begin{array}{l}\delta x \\
(\mathrm{~mm})\end{array}$} & \multirow{2}{*}{$\begin{array}{l}\Delta \\
(\mathrm{mm})\end{array}$} & \multirow{2}{*}{$\begin{array}{l}\Delta \mathrm{a} \\
(\mathrm{mm})\end{array}$} & \multirow{2}{*}{$\begin{array}{l}\Delta \mathrm{a} / \\
\rho \\
(\mathrm{mm})\end{array}$} & \multirow[t]{2}{*}{$\begin{array}{l}\Delta \\
\Delta \mathrm{a} / \rho \\
(\mathrm{mm})\end{array}$} \\
\hline & & & & & & & \\
\hline \multirow[t]{2}{*}{1} & 160 & & & & & & \\
\hline & 0 & 0,00 & 0,00 & 0,00 & 32 & 32 & OK \\
\hline \multirow{2}{*}{$\begin{array}{l}\text { Mezanin } \\
\text { e }\end{array}$} & 300 & & & & & & \\
\hline & 0 & 0,54 & 2,14 & 2,14 & 60 & 60 & OK \\
\hline \multirow[t]{2}{*}{2} & 300 & & & & & & \\
\hline & 0 & 2,39 & 9,56 & 7,42 & 60 & 60 & OK \\
\hline \multirow[t]{2}{*}{3} & 300 & & & & & & \\
\hline & 0 & 4,81 & 19,26 & 9,70 & 60 & 60 & OK \\
\hline \multirow[t]{2}{*}{4} & 300 & & & & & & \\
\hline & 0 & 7,65 & 30,58 & 11,32 & 60 & 60 & OK \\
\hline \multirow[t]{2}{*}{5} & 300 & & & & & & \\
\hline & 0 & 10,75 & 43,02 & 12,44 & 60 & 60 & OK \\
\hline \multirow[t]{2}{*}{6} & 300 & & & & & & \\
\hline & 0 & 14,05 & 56,21 & 13,19 & 60 & 60 & OK \\
\hline \multirow[t]{2}{*}{7} & 300 & & & & & & \\
\hline & 0 & 17,44 & 69,77 & 13,56 & 60 & 60 & OK \\
\hline \multirow[t]{2}{*}{8} & 300 & & & & & & \\
\hline & 0 & 21,03 & 84,14 & 14,36 & 60 & 60 & OK \\
\hline \multirow[t]{2}{*}{9} & 300 & & & & & & \\
\hline & 0 & 24,68 & 98,72 & 14,58 & 60 & 60 & OK \\
\hline \multirow[t]{2}{*}{10} & 300 & & 113,2 & & & & \\
\hline & 0 & 28,32 & 7 & 14,55 & 60 & 60 & OK \\
\hline \multirow[t]{2}{*}{11} & 300 & & 127,4 & & & & \\
\hline & 0 & 31,87 & 8 & 14,21 & 60 & 60 & OK \\
\hline \multirow[t]{2}{*}{12} & 300 & & 141,1 & & & & \\
\hline & 0 & 35,28 & 2 & 13,64 & 60 & 60 & OK \\
\hline \multirow[t]{2}{*}{ atap } & 300 & & 154,0 & & & & \\
\hline & 0 & 38,50 & 0 & 12,87 & 60 & 60 & OK \\
\hline
\end{tabular}

Tabel 8. Kontrol Simpangan akibat Gempa arah Y

\begin{tabular}{|c|c|c|c|c|c|c|c|}
\hline \multirow[t]{2}{*}{ Lantai } & \multirow[t]{2}{*}{ hi } & $\delta x e$ & $\delta x$ & $\Delta$ & $\Delta \mathrm{a}$ & \multirow{2}{*}{$\begin{array}{l}\Delta \mathrm{a} / \\
\rho \\
(\mathrm{mm})\end{array}$} & \multirow{2}{*}{$\begin{array}{l}\Delta \\
\Delta \mathrm{a} / \mathrm{\rho} \\
(\mathrm{mm})\end{array}$} \\
\hline & & $(\mathrm{mm})$ & $(\mathrm{mm})$ & $(\mathrm{mm})$ & $(\mathrm{mm})$ & & \\
\hline \multirow[t]{2}{*}{1} & 160 & & & & & & \\
\hline & 0 & 0,00 & 0,00 & 0,00 & 32 & 32 & OK \\
\hline Mezanin & 300 & & & & & & \\
\hline e & 0 & 0,70 & 2,80 & 2,80 & 60 & 60 & OK \\
\hline \multirow[t]{2}{*}{2} & 300 & & & & & & \\
\hline & 0 & 2,96 & 11,84 & 9,04 & 60 & 60 & OK \\
\hline
\end{tabular}




\begin{tabular}{|c|c|c|c|c|c|c|c|}
\hline \multirow[t]{2}{*}{3} & \multicolumn{3}{|l|}{300} & \multicolumn{4}{|l|}{10,4} \\
\hline & 0 & 5,56 & 22,25 & 1 & 60 & 60 & OK \\
\hline \multirow[t]{2}{*}{4} & 300 & & & 11,2 & & & \\
\hline & 0 & 8,37 & 33,50 & 4 & 60 & 60 & OK \\
\hline \multirow[t]{2}{*}{5} & 300 & 11,3 & & 11,7 & & & \\
\hline & 0 & 1 & 45,24 & 4 & 60 & 60 & OK \\
\hline \multirow[t]{2}{*}{6} & 300 & 14,3 & & 12,0 & & & \\
\hline & 0 & 1 & 57,24 & 0 & 60 & 60 & OK \\
\hline \multirow[t]{2}{*}{7} & 300 & 17,3 & & 11,9 & & & \\
\hline & 0 & 0 & 69,20 & 7 & 60 & 60 & OK \\
\hline \multirow[t]{2}{*}{8} & 300 & 20,4 & & 12,6 & & & \\
\hline & 0 & 5 & 81,81 & 0 & 60 & 60 & OK \\
\hline \multirow[t]{2}{*}{9} & 300 & 23,5 & & 12,5 & & & \\
\hline & 0 & 9 & 94,37 & 6 & 60 & 60 & OK \\
\hline \multirow[t]{2}{*}{10} & 300 & 26,7 & 106,7 & 12,4 & & & \\
\hline & 0 & 0 & 9 & 2 & 60 & 60 & OK \\
\hline \multirow[t]{2}{*}{11} & 300 & 29,7 & 118,8 & 12,0 & & & \\
\hline & 0 & 0 & 0 & 1 & 60 & 60 & OK \\
\hline \multirow[t]{2}{*}{12} & 300 & 32,5 & 130,1 & 11,3 & & & \\
\hline & 0 & 3 & 2 & 2 & 60 & 60 & OK \\
\hline \multirow[t]{2}{*}{ atap } & 300 & 35,1 & 140,4 & 10,3 & & & \\
\hline & 0 & 2 & 9 & 7 & 60 & 60 & OK \\
\hline
\end{tabular}

Dari hasil kontrol tabel di atas maka analisis struktur Hotel Fave Surabaya memenuhi persyaratan sesuai dengan SNI 1726:2012 Pasal 7.9.3 dan Pasal 7.12.1

\section{Disain Struktur Primer}

Hasil analisis struktur dari SAP 2000 adalah gaya dalam (Mu dan $\mathrm{Pu}$ ) yang digunakan untuk mengontrol dimensi balok dan kolom struktur primer. Selain gaya dalam, hasil analisis SAP adalah perilaku struktur, yaitu nilai drift, gaya geser gempa dan partipasi massa .

\section{C.1. Balok}

Kontrol balok induk meliputi: kontrol penampang pelat badan dan sayap $\left(<{ }_{P}\right)$, kontrol kuat lentur akibat tekuk local $(M u<\emptyset . M n)$, kontrol kuat lentur akibat tekuk lateral $(L b<L p)$, kontrol kuat $\operatorname{geser}(V u<\emptyset V n)$, dan kontrol lendutan $\left(f<f_{\text {Maks }}\right)$.

Tabel 9. Disain struktur Balok

\begin{tabular}{|c|c|c|c|c|c|c|c|}
\hline \multirow{2}{*}{ Tipe } & \multirow{2}{*}{ Profil balok } & \multicolumn{3}{|c|}{$\begin{array}{lll}M u & V u & f\end{array}$} & \multirow{2}{*}{$\frac{\emptyset \mathrm{Mn}}{\mathrm{Kg} \cdot \mathrm{m}}$} & \multirow{2}{*}{$\frac{\phi \mathrm{Vn}}{\mathrm{kg}}$} & \multirow{2}{*}{$\frac{\mathbf{f} \mathbf{i j i n}}{\mathrm{cm}}$} \\
\hline & & Kg.m & kg & $\mathbf{c m}$ & & & \\
\hline Tipe 1 & WF300x150x6,5x9 & 7148,8 & 5402,3 & 0,43 & 13051,9 & 26325 & 0,74 \\
\hline Tipe 2 & WF350x175x7x11 & 13362,2 & 10058,7 & 0,56 & 21021,2 & 33075 & 0,74 \\
\hline Tipe 3 & WF400×200x8x13 & 7540,3 & 8365,8 & 1,4 & 32148,8 & 43200 & 0,74 \\
\hline
\end{tabular}

Cek Persyaratan Desain : Mu $<\varnothing \mathrm{Mn}, \mathrm{Vu}<\varnothing \mathrm{Vn}$ dan $\mathrm{f}<\mathrm{f}$ ijin

\section{C.2. Kolom}

Perhitungan kolom induk meliputi: Tekuk Lokal Elemen Tekan pelat badan dan sayap $\left(<{ }_{P}\right)$, Tekuk Lokal Elemen Lentur pelat badan dan sayap $\left(<{ }_{P}\right)$, Tekuk Lateral, Kuat Lentur $(L b<L p)$, Penampang Kondisi Plastis $(M u<\emptyset b . M n)$, Kuat property geometri penampang tekan nominal Pn $\left(\frac{K L}{R} \leq 4,71 \sqrt{\frac{E}{F y}}\right)$, Tegangan Kritis Tekuk - Lentur $\left(\frac{F y}{F e}<2,25\right)$, Tegangan Kritis Tekuk - Puntir $\left(\frac{F y}{F e}<\right.$ 2,25), Kuat Tekan Nominal ( $\mathrm{Pu}<\phi$.Pn), Amplifikasi Momen, dan Interaksi Tekan - Lentur $\frac{P r}{P c}>0,2$.

Tabel 10. Disain struktur Kolom 


\begin{tabular}{ccccccccc}
\multirow{2}{*}{ Ket } & Profil Kolom & Pu & Mux & Muy & Pn & Mrx & Mry & Ratio \\
\cline { 3 - 7 } & kg & kgm & kgm & kg & kgm & kgm & \\
\hline Lantai 1-2 & $\begin{array}{c}\text { Hbeam } \\
500.500 .20 .30\end{array}$ & 476534,5 & 8467,9 & 14630,6 & 938462,0 & 8471,1 & 14636,1 & 0,78 \\
\hline Lobby & WF 400.200.8.13 & 10640,4 & 670,2 & 4763,6 & 1222259,5 & 670,2 & 4763,6 & 0,87 \\
\hline Lantai 3-6 & $\begin{array}{c}\text { Hbeam } \\
500.500 .15 .30\end{array}$ & 34651,6 & 2813,9 & 13200,5 & 860424,8 & 2814,2 & 13201,6 & 0,62 \\
\hline $\begin{array}{c}\text { Lantai 7- } \\
\text { 12 }\end{array}$ & WF 500.300.12.22 & 200239,8 & 2031,4 & 11914,2 & 429745,1 & 2031,4 & 11914,8 & 0,99
\end{tabular}

Cek Persyaratan Desain : Pu $<\varnothing \mathrm{Pn}$, Mux $<\varnothing \mathrm{Mrx}$, Muy $<\varnothing$ Mry dan ratio interaksi aksial lentur $<1$

\section{C.3. Bressing}

Perhitungan bresing meliputi: Kontrol penampang pelat badan dan sayap $\left(<{ }_{P}\right)$, Kontrol kelangsingan penampang $\left(\frac{K x L}{r} \leq \frac{1900}{\sqrt{F y}}\right)$, Parameter kelangsingan dengan faktor tekuk $(\omega)$, Kuat nominal penampang profil $\left(\frac{P u}{\emptyset . P n}<1\right)$, dan Kontrol kuat beban aksial terfaktor $(\mathrm{Pu}<\phi . \mathrm{Pn})$.

Sistem rangka bresing yang digunakan adalah Sistem Rangka Bresing Konsentrik Khusus, dengan type $\mathrm{x}$.

Sesuai dengan hasil output SAP 2000 untuk kombinasi pembebanan ENVELOPE maka gaya dalam yang didapat adalah

$$
\begin{aligned}
& \mathrm{Pu}=-46630,19 \mathrm{Kg} \text { (Tekan) } \\
& \mathrm{Pu}=33872,14 \mathrm{Kg} \text { (Tarik) }
\end{aligned}
$$

Maka Profil yang digunakan adalah Hbeam 200 . 200 10 . 16 dengan fy 250 Mpa dan fu 410 Mpa

\section{C.4. Sambungan}

Untuk sambungan baut diperlukan nilai $\emptyset \mathrm{Vn}$ dan $\emptyset \mathrm{Rn}$. Dari nilai $\mathrm{Rn}$ dan Vn, di ambil nilai yang terkecil guna mencari jumlah baut (n).

$\emptyset . \mathrm{Vn}=0,75$. Vn dimana $\mathrm{Vn}=\mathrm{r} 1 . \mathrm{m}$.Ab.fu baut

$\emptyset \cdot \mathrm{Rn}=0,75 . \mathrm{Rn}$ dimana $\mathrm{Rn}=\varnothing$ baut.2,4 .tp.fu profil

Jumlah baut, $\mathrm{n}=\mathrm{Vu} / \varnothing . \mathrm{Vn}$

Dari hasil analisis, digunakan bressing dengan profil siku penyambung $=\mathrm{L} 80.80 .8$, diameter baut, $\emptyset=16 \mathrm{~mm}$, luasan baut $(\mathrm{Ab})=201 \mathrm{~mm} 2$ dan diameter lubang baut, $\emptyset=18 \mathrm{~mm}, \mathrm{r} 1=0,5$. Jumlah baris $(\mathrm{m})=1$ baris (pada badan balok dan kolom induk)

Mutu Baja profil siku penyambung fy $=250 \mathrm{Mpa}$ dan $\mathrm{fu}=410 \mathrm{Mpa}$

\begin{tabular}{|c|c|c|c|c|c|}
\hline \multicolumn{6}{|c|}{ Tabel 11. Disain sambungan } \\
\hline Sambungan & $\mathrm{Vu}(\mathrm{kg})$ & $\begin{array}{c}\text { Tebal pelat } \\
\text { siku (mm) }\end{array}$ & $\emptyset . V n$ & $\varnothing . \mathbf{R n}$ & $\begin{array}{c}\text { Jumlah baut } \\
\text { (n) }\end{array}$ \\
\hline \multirow[t]{2}{*}{ Balok induk dengan kolom induk } & 10058,6 & 0,6 & 6220,35 & 9446,4 & 2 \\
\hline & 7 & & & & \\
\hline Balok induk dengan balok anak & 8458,59 & 0,6 & 6220,35 & 7084,80 & 2 \\
\hline Balok induk dengan balok induk tangga & 1681,96 & 0,8 & 6220,35 & 7084,80 & 2 \\
\hline \multirow[t]{2}{*}{ Bressing ke kolom induk } & 43630,1 & 1,1 & 12440,7 & 12988,8 & 4 \\
\hline & 9 & & 1 & 0 & \\
\hline
\end{tabular}

Mutu baut A235 fy $=585 \mathrm{Mpa}$ dan fu $=825 \mathrm{Mpa}$ 


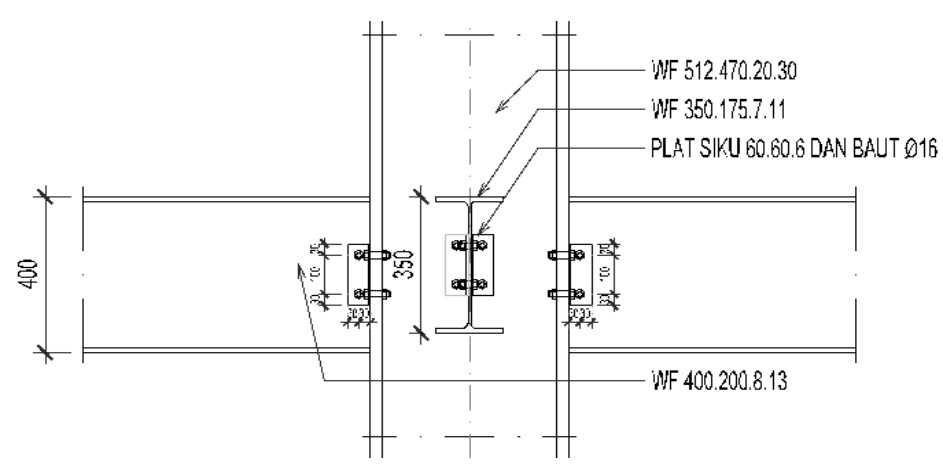

Gambar 3. Sambungan balok induk - kolom induk lantai atap

\section{Kesimpulan}

Dari hasil perhitungan dan analisa yang telah dilakukan, maka dapat diambil kesimpulan sabagai berikut:

1. Dari hasil perhitungan struktur sekunder diperoleh,

Pelat

- Pelat Lantai1 sd mezzanine, tebal 10cm (M10-200)

- Pelat Lantai2 sd atap, tebal 9cm (M8-200)

Balok anak

- Balok anak lantai 1 sd 11, menggunakan WF 350.175.7.11

- Balok anak atap, menggunakan WF 300.150.6,5.9

- Balok lift , menggunakan WF 350.175.7.11

Tangga:

- Pelat anak tangga, Plat tebal $3 \mathrm{~mm}$

- Pelat bordes, Plat tebal $9 \mathrm{~mm}$

- Pengaku anak tangga, menggunakan Siku 50.50.5

- Balok bordes, menggunakan WF 100.50.5.7

- Balok utama tangga, menggunakan WF 200.100.5,5.8

- Balok penumpu tangga, menggunakan WF 200.100.5,5.8

2. Dari hasil perhitungan struktur primer diperoleh

Balok Utama

- Balok utama di Lantai 1-12, balok melintang menggunakan WF 350.175.7.11 dan balok memanjang menggunakan WF 400.200.8.13

- Balok utama di Atap, balok melintang menggunakan WF 300.150.6,5.9 dan balok memanjang menggunakan WF 350.175.7.11.

Kolom Utama

- Kolom utama lantai 1-2 menggunakan Hbeam 500.500.20.30

- kolom lantai 1-2 bagian lobby entrance menggunakan WF 400.200.8.13

- kolom lantai 3-6 menggunakan Hbeam 500.500.15.30

- kolom lantai 7-12 menggunakan WF 500.300.12.22.

Bresing menggunakan Hbeam 200.200.10.16.

3. Perilaku struktur diperoleh

- Partisipasi massa memiliki rasio 99\% > 90\%,

- Periode fundamental mencapai waktu 1,52 detik,

- Gaya geser dasar gempa mencapai lebih dari $85 \%$ gaya geser ijin dengan arah gesernya lebih mengarah ke sumbu X dan Y,

- Simpangan antar lantai terbesar adalah $12,87 \mathrm{~mm}$ sehingga tidak lebih dari simpangan ijin sebesar $38,50 \mathrm{~mm}$.

\section{Referensi}


[1] Badan Standarisasi Nasional. 2002. Tata cara perencanaan struktur baja untuk bangunan gedung (SNI 17292002).

[2] Badan Standarisasi Nasional. 2012. Tata cara perencanaan ketahanan gempa untuk struktur bangunan gedung dan non gedung (SNI 1726 - 2012).

[3] Badan Standarisasi Nasional. 2013. Beban umum untuk perancangan bangunan gedung dan struktur lain (SNI $1727-2013)$.

[4] Badan Standarisasi Nasional. 2015. Spesifikasi untuk bangunan gedung baja struktural (SNI 1729 -2015).

[5] Department pekerjaan umum. 1983. Peraturan pembebanan Indonesia untuk gedung 1983 (PPIUG 1983).

[6] LRFD Manual: Manual of Steel Construction, Load and Resistance Factor Design, 3rd Edition, 2001. (AISCLRFD. 2002)

[7] Rosyd, Moh. 2005. Perencanaan Gedung Parkir Dari Kontruksi Baja Dengan Lokasi Di Ft Unnes Dengan Menggunakan Plat Precast. Semarang: Universitas Negeri Semarang.

[8] J Propika dkk. 2019. Penambahan Stressing Bar pada Perencanaan Struktur baja Gedung Parkir di Institut Teknologi Adhi Tama Surabaya, Prosiding SNTEKPAN ITATS 2019 Surabaya: Institut Teknologi Adhi Tama Surabaya. 